\title{
Factors Affecting Parents' Intention to Choose English Centers: The Role of STEM Education
}

\author{
Tran Do-Van-Anh, Nguyen Ngoc-Duyen, Tang Thai-Ngoc, Le Dinh-Bao-Nhi, \\ Vo Huyen-Yen-Nhi, Le Hoanh-Su*
}

\begin{abstract}
Parents' desire for daily English practice for students and the urge for a etter English education has led to a demand for a highly qualified educational curriculum. In addition to getting deep-dive insights into parents' decision-making process, the increasingly important role of STEM education method has been proved in accordance with plenty of evidenced-based many of previous research. This study was conducted to examine the five independent factors affecting parents' intentions when designating English centers for their children, respectively named: Facility, Teachers, Brands, Social factors and Tuition. Through a preliminary approach, 235 samples were analyzed. Analysis of the sample responses reveals the importance level of five independent factors affecting Parents' intention to choose English centers in descending order: Facilities, Teachers, Brands, Tuition and Social factors. Furthermore, a positive correlation was found between STEM and Intention to choose English centers, indicating that whether the center applies STEM-related curriculum in English courses or not, in fact, has a significant impact on parents' decision. In terms of attitude towards STEM, further statistical tests revealed an interesting finding, which is the fact that how STEM affects Intention of parents is directly proportional to the Attitude towards STEM. With the help of SPSS 20 and AMOS 20, the SEM analysis was processed in order to draw conclusions about factors impacting Intentions to choose English centers. Combining with Multi-group analysis, the major role of STEM education has been assessed in relation to plenty of correlations. In light of recent major and massive growth of English teaching market in Vietnam, several suggestions and recommendations in terms of sustainable developments have been displayed in this research.
\end{abstract}

Key Words: STEM, English education, Intention behavior, SEM, Vietnam.

\section{INTRODUCTION}

Vietnam's intensive involvement in cross-border trade as well as cooperation and multi-lateral agreements shows possible upsurge in language training demand from parents, which invokes potential development of the language training sector in Vietnam EU-Vietnam Business Network [1]. Various studies have assessed language study situations in terms of method, cost and objectives of language learners in Vietnam. Statistically, English training accounts for $96 \%$ of the EFL (English as a Foreign Language) sector, followed by Japanese (15\%), Chinese (10\%) and Korean (8\%) and other languages. When asked about dynamic recruitment market, the majority of domestic and foreign corporates agreed with the statement that more opportunities would possibly be given to candidates who have good command in more than one language. Contrary to expectations, English training in Vietnam is considered as foreign language training only, which requires a manageable teaching - learning model, while integrating language concept and knowledge - based practice claims another upgrading model to transfer to ESL (English as a second language). This could be a reason as to why most children in the metropolis are paved the way for becoming bilingual at a very young age $b$

y their parents (Huh J. H. and Seo K. [2]). Therefore, it is advisable that an elaborate research model towards factors, which could affect parents' decision-making process and behaviors, be carried out with a view to bettering the education method as well as the curriculum used in courses.

In addition to gaining more thorough insights about customers' behaviors, it is likely that STEM has a pivotal role in the decision-making journey when parents designate English centers for kids (Huh J. H. [3]). The existing literature on STEM's effectiveness is intensive and proves that integrated STEM curriculum has a positive impact on academic achievements, reflective

\footnotetext{
Manuscript received March 02, 2020; Revised March 21, 2020; Accepted March 24, 2020. (ID No. JMIS-20M-03-007)

Corresponding Author (*): Hoanh-Su Le, School of Information Systems, University of Economics and Law, Vietnam National University Ho Chi Minh City, Vietnam, +84909511660, sulh@uel.edu.vn

University of Economics and Law, Vietnam National University Ho Chi Minh City, Vietnam, \{anhtdv16410, duyennn16410, ngoctt16410, nhildb16410, nhivhy16410\}@st.uel.edu.vn
} 
thinking skills towards problem-solving and permanence in learning in science education by Sarican and Akgunduz [4]. To date, it has been argued that whether children's language skill could be developed and changed through cause-effect scenarios or absorbing knowledge from different fields. A great deal of previous research into this aspect have been performed and researchers found out that integrating STEM might be a new way for children to enhance experiences, cognitive skill (language) and expression. As learners trying to integrate concepts and language, adding new concepts through language becomes progressively much easier as the linguistic skills and abilities of the learner increase by time. The learner owns a wider and more deep-dive foundation upon which to layer new concepts and language Coady et al. [5]. For ELs (English learners), success often depends on engaging in the classroom and outdoor activities which could encourage them to draw on the languages and multicompetencies they already take hold of and to link new conceptions with the knowledge they have been taught at school or from communities, e-learning (Moll et at. [6], HS Le et al. [7]). According to and KOFAC's report Hong [8] towards STEM's impact in education, students who participated in classes or lessons applied STEM proved that there was more of extraordinary science - oriented thinking competence commencing, compared to students who did not take part in. It is reported that at least 16 primary and lower secondary schools are experimenting STEM education under the joint supervision of the MOET and British Council in 2018 and Huh, J. H. [9]. Strong evidence of the increasing focus on STEM model in language training in the Vietnam market could be indicated through this result. Hence, there might be an unambiguous relationship between STEM method and English training procedure, which possibly could become a competitive advantage for English centers which have the desire for revitalizing the teaching-learning model as well as curriculum applied in courses.

This study could benefit specialists and business owners in many different aspects in terms of improving service quality or prepare for an intensive expansion in the language training sector. First and foremost, the study discerns the five factors which contribute to the decisionmaking process of parents when choosing English centers for kids. Secondly, this study observes STEM in relation to those factors to assess its influence, then ranked all factors based on the level of importance and effect in order for business corporates to prioritize which aspects they should focus on, explaining the indisputable role of STEM in English training process. Thirdly, a number of recommendations and solutions from the perspective of corporates have been allocated to develop and create a more sustainable strategy in the future, along with a more appropriate marketing strategy for customers' consumption, meeting with suitable requirements. To distinguish the correlations between independent factors, several concerns have been inserted in this study, answering key questions "What are the factors influencing parents' decision when choosing English centers?", "To what extent is STEM education becoming more and more essential in decision-making journey of parents?", "What are the possible aspects which should be remedied by educational corporates and business?".

In the next section of this paper, the literature review would be introduced to readers, followed by research methodology, findings being carried on. Finally, conclusions, limitations and future directions for the upcoming research would be presented.

\section{LITERATURE REVIEW}

\subsection{Rational Choice (RC)}

Homans [10] was the first one to introduce the rational choice theory in 1961 . The theory emphasizes that the more often a particular action of a person is rewarded, the more likely the person is to perform that action. Furthermore, if an action has a higher possibility, that person has a tendency to choose to perform the action although its other values are not as worthy as expected.

Another research by Friedman \& Hechter [11] specified other common values that individuals pursue. Individuals would evaluate the options and switch to another possibility if the previous one was not suitable for their present situation.

\subsection{Theory of Reasoned Action (TRA)}

In a study by Fishbein and Ajzen [12], the aspects of quality were measured through importance level performance level. An individual will evaluate each of the aspects to assess how beneficial it is to their total benefits. Generally, if the aspect has a low score for importance level, clearly it affects insignificantly to an individual's perception and vice versa.

It is concluded that the most crucial factor controlling human's decision is the intention to perform the action, which can be affected by the attitude towards action and the subjective norms related to the action.

\subsection{Consumer Behavior Model}

The consumer behavior model developed by Philip Kotler and Gary Armstrong [13] proved that human 
behavior based on both External environmental factors (4P, Macro factors) and Internal factors (Individual characteristics, social, cultural and psychological characteristics). Information was input to the customer's "black box". When in there, the information impacts the perceiving process and forms a responsive reaction from the customer.

\subsection{A Model of Student College Choice}

In 1981, D. Chapman [14] introduced one of the first models with a view to assessing college students' choice. Chapman's model is based on the interaction between the students' characteristics of socioeconomic status, aptitude, educational aspiration and achievement and a series of external influences. These external influences can be grouped into three general categories: 1) significant other - friends, parents, high school teachers and counselors; 2) fixed characteristics of the institution cost (financial aid), location, program availability; and 3) communication efforts of the college - campus visits, written information, admissions and recruiting activities. The interactive effects of the factors in this model appear to directly influence the student's choice of college.

\subsection{Proposed Research Model}

Based on the results from several studies by Sia [15]; Joseph and Joseph [16]; Hanson and Litten [17]. It can be concluded that the Chapman's model of student college choice (1981) [14] are of great efficiency. Thus, this paper attempts to develop a conceptual model on parent's choice of English Center for their children in Vietnam. This conceptual model to be developed will adapt and modify the model developed by Chapman and added some factors that match the particular characteristics of the Vietnamese children in the present time. The study below shows the relationship between the main dependent factor (intention in choosing the English center) and the five independent factors (facilities, brands, teachers, tuition, social factors). Then the moderator variable was added in the model (STEM education) to show the differences between these factors and the intention to choose an English Centers which are applied and non-applied STEM in its program.

\subsubsection{Facilities}

A study conducted by Absher and Crawford [18] found that educational facilities such as classrooms, laboratories and libraries are important in a student's selection of a college or university. Thus, this study hypothesizes that facilities are a significant predictor that influences parents' intention.
H1: The facilities have positive influences on parents' intention to choose English centers.

\subsubsection{Brands}

In several researches by Burns [19] and Sia [15] concluded that the importance of institutional brands as the main driving factor for students in choosing the relevant place to study. They all agreed that a university's brand was a powerful factor in affecting students' choices.

Based on the findings mentioned above, it is hypothesized that brand is a significant predictor that influences parents' intention to choose English centers for their children.

H2: The brands have positive influences on parents' intention to choose English centers.

\subsubsection{Teachers}

A great deal of research has been conducted on teachers and student evaluations of teachers (Curran and Rosen [20]; Cashin and Downey [21]; Sees et al. [22] and it has been established that student reactions to teachers are important to almost every institution of higher learning. The existence of this relationship justifies the fact that teachers are significant predictors that influences parents' intention.

H3: The teachers have positive influences on parents' intention to choose English centers.

\subsubsection{Tuition}

Joseph \& Joseph [16] recognized that cost-related issues seem to have more importance as the years go by. For instance, Chapman [14] and Yusuf et al. [23] identified the quality of the institution and cost as the most important elements. As a result, this study hypothesizes that cost is a significant predictor that influences college choice decisions.

H4: The tuition has positive influences on parents' intention to choose English centers

\section{5. 5. Social factors}

Social relationships, whether with family, relatives or friends who are in the destination country can affect the student's decision to study in their country Lee \& Morrish [24]. The information and support from family and friends are seen as an element of trust that has a strong influence on individual perception. Other study conducted by Yufuf \& et al [23] stated that the influence from peers, families and friends is really strong and will affect the student's decision in choosing higher education. As a result, this study hypothesizes that social factors are significant predictors that influences parents' intention.

H5: The social factors have positive influences on parents' 
intention to choose English centers.

\section{5. 6. STEM Education}

Se studies have concurred that the availability of suitable programs could be considered as an important factor to the choice of college Sia [15].

Freeman et al. [25] using a meta-analysis of 225 STEM education studies, concluded that active learning approaches are robustly superior in regard to reducing course failure rates and increasing student learning in STEM disciplines. As the hypothesized model shows, the course topic is as important as the instructor and should, therefore, be considered as a key element driving students' reactions.

H6: There are significant differences in the relationship between five factors and parents' intention to choose English centers for their children which use STEM education program.

A total of five (5) research hypotheses were developed to investigate the relationships of these independent variables affecting the parents' decision in choosing the English Center for their children as Fig. 1.

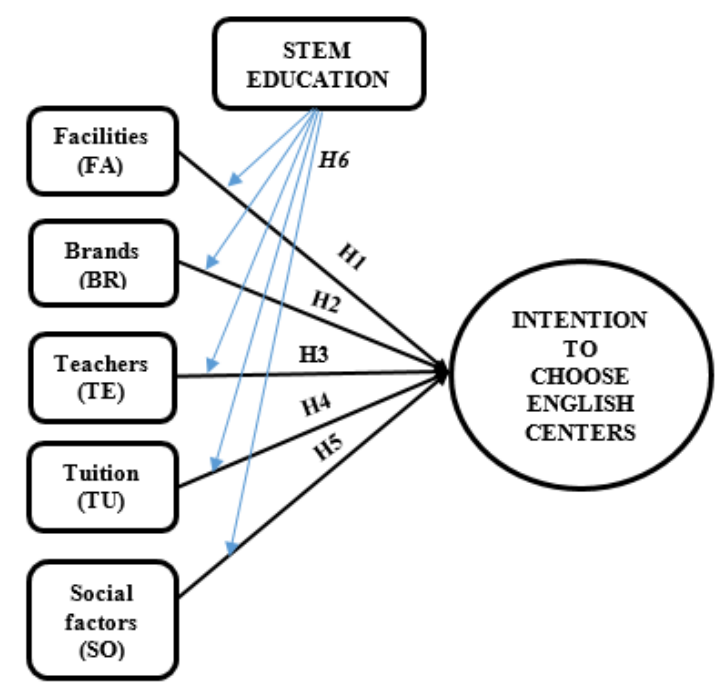

Fig. 1. The research model and hypothesis.

\section{RESEARCH METHODOLOGY}

The research was performed through preliminary research using qualitative methods and official research using quantitative methods. Preliminary research was aimed at adjusting and checking the accuracy of the scale, defining accurately the factors that influence the intention to choose an English center and the role of integrating STEM education into teaching as well as. In addition, preliminary research was also aimed at eliminating unnecessary elements and complementing new elements to the model. The goal of quantitative research methods is to place emphasis on numbers and figures in the collection and analysis of data. Data were collected from 235 samples - parents whose kids' were taking part in courses at English centers in Ho Chi Minh City through a convenient and geographical sampling method on a scale of eight districts within the city.

Responses to different variables related to the perceptions of the individual subjects were measured using a 5-point Likert scale. After collecting 235 samples, data were processed and analyzed through the Cronbach's alpha and Exploratory Factor Analysis (EFA) respectively using the Statistical Package for the Social Sciences (SPSS) software to test the proposed research model. In the following steps, we applied AMOS 20 into further analysis which are CFA, SEM, Bootstrap and Multi-group Analysis.

In CFA analysis, we measured proposed research model with a view to testing composite reliability, convergent validity and discriminant validity. In terms of SEM model, we tested hypotheses related to clausal relationship and evaluated impact levels. For Bootstrap testing, we tested proposed model once again based on random sampling with replacement. Last but not least, Multi-group analysis was applied for two main reasons: (1) prove that STEM effects intention to choose English centers (2) prove that there are differences between two target groups: appliedSTEM and non-applied-STEM English centers.

The paper's research hypotheses include Facility, Reputation, Teacher, Tuition, Social Factors, Intention to choose, Awareness of Stem, Attitude towards STEM, Effect of the educational program together with 34 variables observed with the following research process:

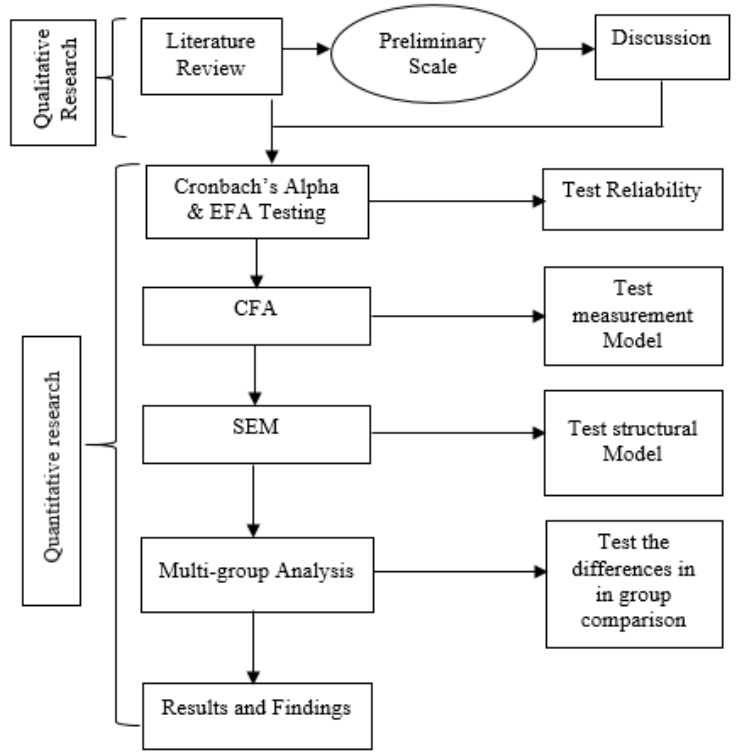

Fig. 2. Research Methodology.

Questions to assess factors relating to STEM were created based on Likert Scale (assessment level from 1 to 
5), in response to 235 samples towards 11 STEM-related questions, including: 4 questions regarding parents' perception of STEM education; 3 questions regarding parents' attitude towards STEM education; 4 questions regarding the results of education programs that children are entering.

\section{FINDINGS AND DISCUSSION}

\section{1. Samples Information}

The survey completes with 235 valid samples including 125 males (53.2\%), 110 females (53,0\%); Most respondents were at the age group of 30-45 years $(70,2 \%)$. Most respondents had an income in the range 430\$ - 1 $292 \$$ of per month (both income of wives and husbands), $35.3 \%$ has income ranging from $430 \$$ to $861 \$$ / per month and $38.7 \%$ has income approximately ranging from $862 \$$ to $1292 \$ /$ per month.

\section{2. Descriptive Analysis}

From questions related to STEM education to assess the level of awareness, attitudes, and effectiveness of STEM education, we have the following results:

\begin{tabular}{|l|c|c|c|}
\hline & $\begin{array}{c}\text { Researched } \\
\text { samples } \\
(\mathrm{N}=235)\end{array}$ & $\begin{array}{c}\text { Non-applied- } \\
\text { STEM } \\
\text { sampling } \\
\text { group } \\
(\mathrm{N}=124)\end{array}$ & $\begin{array}{c}\text { Applied- } \\
\text { STEM } \\
\text { sampling } \\
\text { group } \\
(\mathrm{N}=111)\end{array}$ \\
\hline $\begin{array}{l}\text { Perception } \\
\text { towards } \\
\text { STEM } \\
\text { education }\end{array}$ & 2.46 & 1.93 & 3.06 \\
\hline $\begin{array}{l}\text { Attitude } \\
\text { towards } \\
\text { STEM } \\
\text { education }\end{array}$ & 2.65 & 2.27 & 3.07 \\
\hline $\begin{array}{l}\text { Effectiveness } \\
\text { of the } \\
\text { educational } \\
\text { program }\end{array}$ & 3.67 & 3.43 & 3.94 \\
\hline
\end{tabular}

Fig. 3. Means value of STEM - Related factors.

As can be seen from the table, STEM is still an emerging teaching method in Vietnam for educating and learning English market. Parents who decide to register for their kids in English centers applying STEM mostly are well or highly - educated people, they also have positive perception and attitude towards STEM method. Thus, those parents assess that English centers applying STEM curriculum have brought far better results compared to others.

\section{3. Confirmatory Factor Analysis}

Observed variables of independent variables have an influence on Intention to choose, which were formed based on Likert scale (assessment level from 1 to 5). After the data was encoded and cleaned, our team conducted the analysis on 235 samples used for official quantification to perform Cronbach's Alpha reliability analysis. After eliminating unsuitable variables and processing Cronbach's Alpha once again, the results of the reliability analysis of the scale are presented in the table below:

Table 1. Reliability results.

\begin{tabular}{|l|c|c|c|}
\hline \multicolumn{1}{|c|}{ Scales } & $\begin{array}{c}\text { Number of } \\
\text { variables }\end{array}$ & $\begin{array}{c}\text { Cronbach's } \\
\text { Alpha }\end{array}$ & Means \\
\hline Facilities (FA) & 3 & 0.764 & 3.867 \\
\hline Brands (BR) & 3 & 0.810 & 4.197 \\
\hline Teachers (TE) & 3 & 0.819 & 4.138 \\
\hline \begin{tabular}{l} 
Tuition (TU) \\
\hline $\begin{array}{l}\text { Social Factors } \\
\text { (SO) }\end{array}$
\end{tabular} & 3 & 0.834 & 3.650 \\
\hline $\begin{array}{l}\text { Intention to } \\
\text { choose (IC) }\end{array}$ & 3 & 0.848 & 3.965 \\
\hline
\end{tabular}

From the above Table 1, it can be seen that all scales are reliable (> 0.6). The parameters were set as Chisquare $=229.965 ; d f=120 ; P=000 ;$ Chi-square $/ d f=1.916$, $G F I=0.898 ; T L I=0.919 C F I=0.936$; $R M S E A=0,063$. Chisquare/df <2; p <0.05; GFI = 0.898, CFI > 0.95, RMSEA $<0.8$, all $\mathrm{CR}>0.7$ and all AVE > 0.5. In addition, all measures are significant on their path loadings at the level of 0.001 . Besides, results in testing discriminant validity shows that all squared correlations between two constructs are less than the average variance extracted of both constructs. Therefore, the results confirm that the convergent validities, discriminant validity of constructs in the study is satisfactory.

\begin{tabular}{|l|l|l|l|l|l|l|l|}
\hline & C.R & 1 & 2 & 3 & 4 & 5 & 6 \\
\hline $\begin{array}{l}\text { l. Facilities } \\
\text { (FA) }\end{array}$ & $\mathbf{0 . 7 8 8}$ & $\mathbf{0 . 5 5 5}$ & & & & & \\
\hline $\begin{array}{l}\text { 2. Brands } \\
\text { (BR) }\end{array}$ & $\mathbf{0 . 8 1 7}$ & 0.063 & 0.601 & & & & \\
\hline $\begin{array}{l}\text { 3. Teachers } \\
\text { (TE) }\end{array}$ & $\mathbf{0 . 8 2 4}$ & 0.066 & 0.066 & $\mathbf{0 . 6 1 2}$ & & & \\
\hline $\begin{array}{l}\text { 4. Tuition } \\
\text { (TU) }\end{array}$ & $\mathbf{0 . 8 3 7}$ & 0.065 & 0.065 & 0.065 & $\mathbf{0 . 6 3 1}$ & & \\
\hline $\begin{array}{l}\text { 5. Social } \\
\text { Factors } \\
\text { (SO) }\end{array}$ & $\mathbf{0 . 8 5 0}$ & 0.065 & 0.065 & 0.065 & 0.065 & $\mathbf{0 . 6 5 8}$ & \\
\hline $\begin{array}{l}\text { 6. Intention } \\
\text { to choose } \\
\text { (IC) }\end{array}$ & $\mathbf{0 . 7 5 2}$ & 0.055 & 0.058 & 0.060 & 0.060 & 0.064 & $\mathbf{0 . 5 0 6}$ \\
\hline
\end{tabular}

Fig. 4. The results CFA analysis. 


\section{4. Structural Equation Modeling}

With the appropriate indicators obtained in the SEM analysis step, it can be concluded that this model is consistent with market data and that $70.4 \%$ of the variance of the intention to use is explained by the remaining factors in the model.

\begin{tabular}{|l|l|l|l|l|l|l|}
\hline & $\begin{array}{c}\text { Regression } \\
\text { Weight }\end{array}$ & $\begin{array}{c}\text { Standardized } \\
\text { Regression } \\
\text { Weight }\end{array}$ & S.E. & C.R. & P & Results \\
\hline IC < - SO & 0.117 & 0.254 & 0.031 & 3.739 & $* * *$ & Supported \\
\hline IC <- TU & 0.114 & 0.248 & 0.031 & 3.680 & $* * *$ & Supported \\
\hline IC <- TE & 0.256 & 0.423 & 0.045 & 5.654 & $* * *$ & Supported \\
\hline IC <- BR & 0.127 & 0.290 & 0.032 & 3.921 & $* * *$ & Supported \\
\hline IC <- FA & 0.192 & 0.453 & 0.034 & 5.571 & $* * *$ & Supported \\
\hline
\end{tabular}

Fig. 5. Results of hypothesis testing.

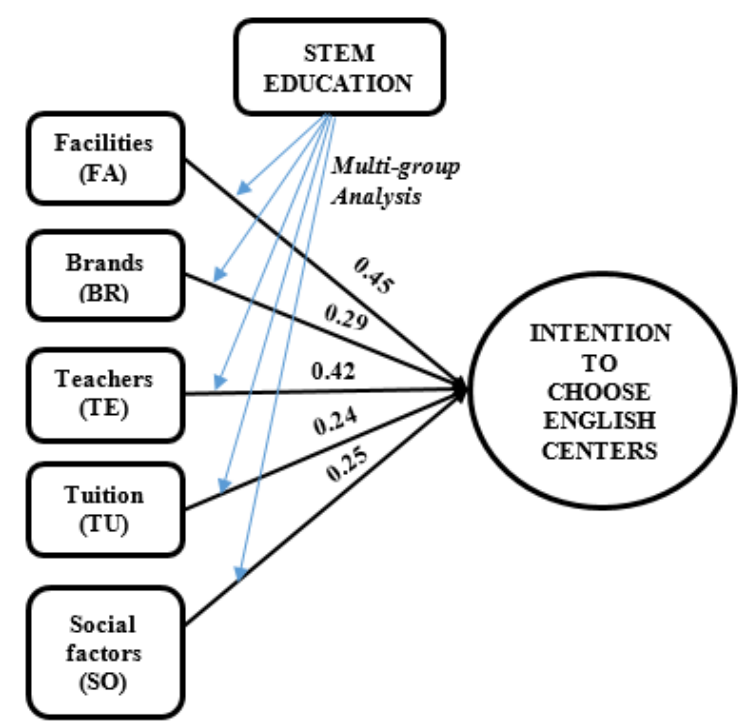

Fig. 6. Research model with factor loading and significance.

\section{5. Multi-group Analysis}

To assess the impact of moderating variable STEM, as well as to consider the difference between the two models, one of which apply STEM while the other one did not, we progressed towards Multi-group analysis with a view to giving conclusions about hypotheses.

Table 4 provides a comparison between invariance analysis and variance analysis towards sampling group applying STEM and sampling group which does not apply STEM. Thus, we come to a conclusion about the difference. After that, table 5 clarifies value differences between the mentioned two groups.

\begin{tabular}{|c|c|c|c|c|c|c|c|c|}
\hline \multicolumn{2}{|c|}{ Basic model } & $\varkappa^{2}$ & Df & RMSEA & GFI & CFI & $\chi^{2}$ /df & $\mathrm{Pa}$ \\
\hline \multirow[b]{2}{*}{$\begin{array}{l}\text { Multi } \\
\text { group }\end{array}$} & & 229.965 & 120 & 0.063 & 0.898 & 0.936 & 1.916 & 0.000 \\
\hline & Model & $\varkappa^{2}$ & Df & RMSEA & GFI & CFI & $\Delta y^{2} / \Delta \mathrm{df}$ & $\mathrm{Pa}$ \\
\hline \multirow{2}{*}{$\begin{array}{c}\text { Non- } \\
\text { applied- } \\
\text { STEM } \\
\text { Applied- } \\
\text { STEM } \\
\end{array}$} & Invariant & 381.669 & 245 & 0.049 & 0.845 & 0.918 & \multirow[b]{2}{*}{4.228} & \multirow[b]{2}{*}{0.001} \\
\hline & Variant & 360.528 & 240 & 0.046 & 0.855 & 0.928 & & \\
\hline \multicolumn{2}{|c|}{ Value difference } & 21.141 & 5 & 0.003 & 0.01 & 0.01 & & \\
\hline
\end{tabular}

Fig. 7. Structural Equations Results for Moderating Effect Models.

The value $\mathrm{Pa}=0.001(<0.05)$ so the Variant model is selected. Therefore, there are differences in the model of factors affecting the intention to choose English centers between groups with and without applying STEM education.

\begin{tabular}{|l|c|c|c|c|c|c|}
\hline & $\begin{array}{c}\text { Regression } \\
\text { Weight }\end{array}$ & $\begin{array}{c}\text { Standardized } \\
\text { Regression } \\
\text { Weight }\end{array}$ & S.E. & C.R. & P & Results \\
\hline \multicolumn{7}{|c|}{ Non-applied-STEM } \\
\hline IC < - SO & 0.050 & 0.333 & .025 & 2.012 & 0.044 & Supported \\
\hline IC < - TU & 0.008 & 0.047 & .019 & .442 & 0.659 & $\begin{array}{c}\text { Not } \\
\text { Supported }\end{array}$ \\
\hline IC < - TE & 0.131 & 0.533 & .056 & 2.325 & 0.020 & Supported \\
\hline IC < - BR & 0.048 & 0.329 & .023 & 2.066 & 0.039 & Supported \\
\hline IC < FA & 0.079 & 0.597 & .033 & 2.389 & 0.017 & Supported \\
\hline & \multicolumn{7}{|c|}{ Applied-STEM } \\
\hline IC < - SO & 0.133 & 0.200 & .058 & 2.283 & 0.022 & Supported \\
\hline IC < - TU & 0.272 & 0.405 & .065 & 4.160 & $* * *$ & Supported \\
\hline IC < - TE & 0.193 & 0.292 & .058 & 3.317 & $* * *$ & Supported \\
\hline IC < BR & 0.078 & 0.132 & .067 & 1.154 & 0.248 & $\begin{array}{c}\text { Not } \\
\text { Supported }\end{array}$ \\
\hline IC < - FA & 0.265 & 0.412 & .079 & 3.375 & $* * *$ & Supported \\
\hline
\end{tabular}

Fig. 8. Comparison table between 2 researched sampling groups.

\section{CONCLUSION \& SOLUTION}

\subsection{Conclusion}

The strong factors affecting the intention to choose English center in Vietnam in descending order which are: Facilities (0.453), Teachers (0.423), Brands (0.290), Social factors (0.254) and Tuition (0.248). As can be seen, Facilities is the strongest factor affecting Intention. Tuition is the weakest factor. This leads to our conclusion that in English teaching market in Vietnam, Facilities is the key factor that gives parents first positive impression when they come to an English center looking for counseling, as well as a great way to attract customer's 
attention and gradually make people have faith in the center.

From the results withdrawn from Multi-group analysis, we discovered there were significant difference between two groups (Non-applied-STEM and Applied-STEM). Specifically, it can be concluded as below:

To non-applied-STEM sampling group, Tuition did not have any effect on Intention. The rest of variables influenced Intention were ranked in descending order: Facilities, Teachers, Social factors, Brands.

This can be explained that, in Vietnam, any English centers which want to apply new curriculums like STEM will spend a lot of money on training teachers and investing facilities. Thus, the tuitions need to be increased to meet the cost. Also, parents do not truly pay much attention to tuition fees since they can be able to afford it already, as opposed to the STEM centers where tuition fees are always higher (a bit higher than the average fees of the teaching and studying English in Vietnam). Thus, parents tend to consider many times in terms of financial statements if they would like to register for their kids. In conclusion, STEM education is seen to be a solution for small and new English centers that is finding the position in Vietnam, that will be a different point with others. STEM will resolve the problems in discounting tuition to compete with rivals, also increase the value of center's brand. Students' parents will have a positive image of centers.

\subsection{Recommendations}

Regarding 5 factors that influence the parents' intention to choose an English center for children, we suggest some recommendations to maximize the benefits from these factors.

Facilities need to be upgraded to meet standards of classrooms and teaching equipment. A learning app on the phone interface is needed to help children interact more with the subject through puzzle games, avoiding homework assignments, etc. Another suggestion is applying technology by communicating with parents through remote student management programs, helping parents keep track of their children's learning schedules. The program can be built through applications or accounts on the website.

Teachers must meet certain degree requirements. Adopting some regular training courses to improve and reexamine teacher qualifications is the first step. After that, centers should create exchange days between native teachers and Vietnamese teachers to learn each other's teaching way.
Brands should be developed comprehensively. It is important to rookie centers who have just entered the market to create a brand image associated with "highly well-equipped centers with diverse foreign resources from teachers to adopted methods and facilities" with a view to getting trust from parents.

About Social factors, we recommend that building professional communication channels, and organizing events should be enhanced for getting a higher level of customer awareness of the brand. Call center support should be well completed to advise customers in the best way possible.

To improve Tuition factors, we suggest centers to have multiple tuition packages (by month, by course, by age). This will increase the competitiveness of the center compared to the rest. Adding some tuition support policies for excellent students or new students to create appeal is also a great way to start.

As can be withdrawn from the above conclusions, applying STEM into curriculum brings undeniably positive results for kids who took part in the course. Therefore, applying STEM into further teaching would join hands for enhancing the quality of both teaching and learning. Thus, centers could manufacture a fiercely competitive advantage among other competitors in the context of the diverging market in Vietnam.

Besides, parents choosing STEM centers usually are well-educated people, already having positive perceptions towards this method. Thus, English centers should consider bringing more forward-looking images of STEM education through different communicative approaches such as an event, conference, experimental class for STEM, learning application, social media tools, etc.

However, English centers applying STEM education must consider parents' financial statements when it comes to significantly high tuition fees, along with top-notch teaching quality. Centers could attach more flexible tuition fee packages. For example, parents can choose semester packages instead of whole year packages; choose to have installment packages. Besides, centers could support parents in terms of course promotions. For instance, if parents register for the next course, they will get promotions; if parents register during the low season, they will also get benefits, etc.

\section{LIMITATIONS AND FUTURE RESEARCH}

Due to limited human resources, we focused on convenience sampling (including 8 districts in Ho Chi Minh City), which led to the fact that the sample does not make much sense. Ho Chi Minh City is a metropolis with 
the diffusing population so we could only carry out our survey in certain districts.

Furthermore, STEM education is still an experimental education method in Vietnam. In fact, there are few educational corporates applying STEM into their curriculum. Therefore, we encountered multiple difficulties in finding English centers applying STEM education with a view to distributing our survey forms. Because the number of people who have heard of STEM education is not significantly enormous, it took us quite a long time to give them a depiction of how STEM operates.

In conclusion, there are many flaws existing within this case. However, we would do our best in order to develop and diversify the aspects of this model. Instead of convenience sampling method, we would give it our best shot to reach a wider target audience. Last but not least, we would expand our model using more variables such as Age and Geographic features, to explain more clearly and point out more differences among groups.

For future research directions, this research will overcome the model's remaining limitations, especially, it will be developed and diversified the aspects of the model. Instead of using convenience sampling method, it can be developed to reach the target audience more effectively. In addition, in-depth research on STEM-related factors would be conducted, as well as clarify the differences between Applied-STEM and non-applied-STEM in English centers curriculum to clarify the influential role of STEM education in parents' intention to choose English centers.

This research would be expanded to use more variables such as demographic characteristics, geographic features, personality traits or personal characteristics, consumer buying behavior... to explain more clearly and point out more difference among groups.

\section{REFERENCES}

[1] Network, E.-V. B., "EVBN Report Education Final Report," www.evbn.org, 2019.

[2] Huh, J. H., \& Seo, K. "Development of competencyoriented social multimedia computer network curriculum." Journal of Multimedia Information System, vol. 1, no. 2, pp. 133-142, 2014.

[3] J. Huh and K. Seo, "Smart Grid Framework Test Bed Using OPNET and Power Line Communication," 2016 Joint 8th International Conference on Soft Computing and Intelligent Systems (SCIS) and 17th International Symposium on Advanced Intelligent Systems (ISIS), Sapporo, pp. 736-742, 2016.

[4] Sarican. G. and Akgunduz D., "The impact of integrated STEM education on academic achievement, reflective thinking skills towards problem solving and permanence in learning in science education," Cypriot Journal of Educational Sciences, vol. 13, no. 1, pp. 94$113,2018$.

[5] Coady M. R., Harper C., and De Jong E. J., “Aiming for equity: Preparing mainstream teachers for inclusion or inclusive classrooms?" Tesol Quarterly, vol. 50, no. 2, pp. 340-368, 2016.

[6] Moll L.C. and Greenberg J., Creating zones of possibilities: Combining social contexts for instruction, In L.C. Moll (Ed.), Vygotsky and education, Cambridge, U.K.: Cam- bridge University Press, pp. 319-348, 1991.

[7] HS Le, T. N. Manh, and H. K. Lee, "Motivations Triggering Electronic Word of Mouth Intention: A Study for E-Learning Websites at Vietnam," Korean Bussiness Review, vol 19, no 1, pp. 97-123, 2014.

[8] Hong O., "STEAM education in Korea: Current policies and future directions," Science and Technology Trends Policy Trajectories and Initiatives in STEM Education, vol. 8, no. 2, pp. 92-102, 2017.

[9] Huh, J.H. "Information communication ethical study on the protection of digital copyrights and alternatives: focusing on the secondary school students." Journal of Multimedia Information System, vol. 3, no. 2, pp. 2734, 2016.

[10] Homans G. C., "Its elementary forms," Social Behavior, vol. 119, no. 3, pp. 488-531, 1961.

[11] Friedman D. and Hechter M., "The contribution of rational choice theory to macrosociological research," Sociological Theory, vol. 6, no. 2, pp. 201-218, 1988.

[12] Fishbein M. and Ajzen I., Intention and Behavior: An introduction to theory and research, Addison-Wesley, Reading, MA, 1975.

[13] Kotler P. and Armstrong G., Principles of Marketing, 14th Edition, Pearson Education Limited, Essex, England, 2012.

[14] Chapman D. W., "A Model of Student College Choice," Journal of Higher Education, vol. 52, no. 5, pp. 490-505, 1981.

[15] Ming J. S. K., "Institutional factors influencing students' college choice decision in Malaysia: A conceptual framework," International Journal of Business and Social Science, vol. 1, no. 3, pp. 52-58, 2010.

[16] Joseph M. and Joseph B., 'Indonesian students' perceptions of choice criteria in the selection of a tertiary institution: Strategic implications," International Journal of Educational Management, vol. 14, no. 1, pp. 40-44, 2000.

[17] Hanson K. and Litten L., Mapping the road to academia: A review of research on women, men, and the college selection process, N P. Perun (Ed.), The 
undergraduate woman, Issues in education. Lexington, MA: Lexington, 1982.

[18] Absher K. and Crawford G., "Marketing the community college starts with understanding students' perspectives," Community College Review, vol. 23, no. 4, pp. 59-68, 1996.

[19] Burns M. J., Factors influencing the college choice of African-American students admitted to the college of agriculture, food and natural resources, University of Missouri-Columbia, 2006.

[20] Curran J. M. and Rosen D. E. "Student attitudes toward college courses: An examination of influences and intentions," Journal of Marketing Education, vol. 28, no. 2, pp. 135-148, 2006.

[21] Cashin W. E. and Downey R. G., "Using global student rating items for summative evaluation," Journal of educational Psychology, vol. 84, no. 4, pp. 563-572, 1992.

[22] Sees K. L., Delucchi K. L., Masson C., Rosen A., Clark H. W., Robillard H., Hall S. M., "Methadone maintenance vs 180-day psychosocially enriched detoxification for treatment of opioid dependence: a randomized controlled trial," Jama, vol. 283, no. 10, pp. 1303-1310, 2000.

[23] Yusuf B. N. M., Ghazali M. Q. M., and Abdullah M. F. S., "Factors Influencing Local and International Students Decision in Choosing Public Higher Learning Institutions in Northern Region of Malaysia," International Journal of Social Sciences, vol. 48, no. 1, pp. 29-41, 2017.

[24] Lee C. K. C. and Morrish S. C., "Cultural values and higher education choices: Chinese families," Australasian Marketing Journal (AMJ), vol. 20, no. 1, pp. 59-64, 2012.

[25] Freeman S, Eddy S. L., McDonough M., Smith M. K., Okoroafor N., Jordt H., Wenderoth M. P., "Active learning increases student performance in science, engineering, and mathematics," PNAS, vol. 111, pp. 8410-8415, 2014.

Authors

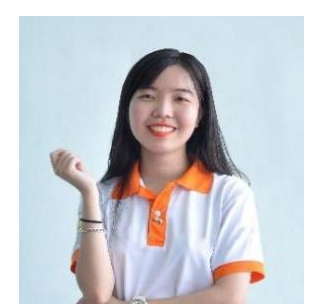

Tran Do-Van-Anh is currently final year student of High-Quality Program at the Department of Marketing at University of Economics and LawVNUHCM. Her research interest is social development, social psychology, marketing communication.

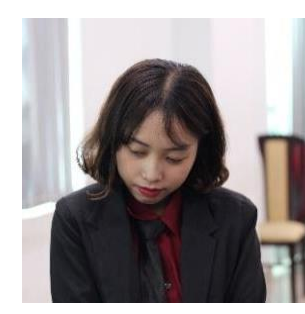

Nguyen Ngoc-Duyen is currently final year student of High-Quality Program at the Department of Marketing at University of Economics and LawVNUHCM. Her research interest is in human resources, customer behavior and marketing research.

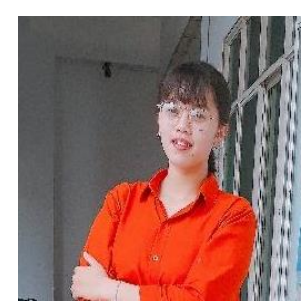

Tang Thai-Ngoc is currently final year student of High-Quality Program at the Department of Marketing at University of Economics and Law-VNUHCM. Her research interest is education service, customer service and marketing communication.

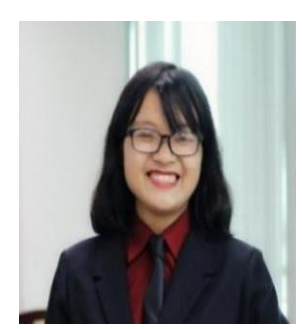

Le Dinh-Bao-Nhi is currently final year student of High-Quality Program at the Department of Marketing at University of Economics and Law-VNUHCM. Her research interest is in business analytics, data analytics and customer behavior.

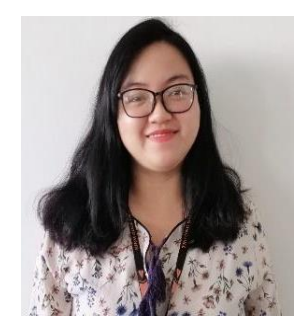

Vo Huyen-Yen-Nhi is currently final year student of High-Quality Program at the Department of Marketing at University of Economics and LawVNUHCM. Her research interest is multimedia design, artificial intelligence research, IoT in education.

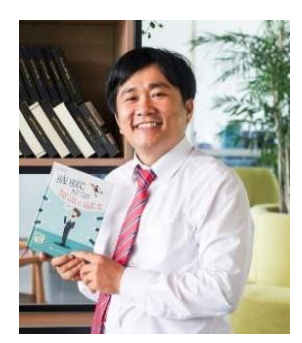

Le Hoanh-Su (sulh@uel.edu.vn) received the B.E in Electronics and Telecommunication, MSc in MIS and MBA degrees from Vietnam National University HCM City in 2013, the Ph.D. degrees in E-business from Pukyong National University, South Korea. From 2006 to 2011, he was Senior Engineer, Project Team Leader at Global CyberSoft and since 2011 he has been a faculty member, and currently Vice Dean of School of Information Systems of University of Economics and Law-VNUHCM. His research interests are in the areas of data analytics, big data, robotics and AI. 
Factors Affecting Parents' Intention to Choose English Centers: The Role of STEM Education 